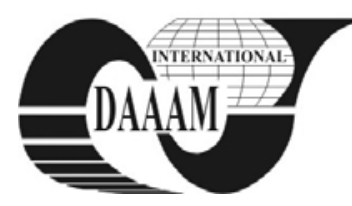

Annals of DAAAM for 2011 \& Proceedings of the 22nd International DAAAM Symposium, Volume 22, No. 1, ISSN 1726-9679 ISBN 978-3-901509-83-4, Editor B. Katalinic, Published by DAAAM International, Vienna, Austria, EU, 2011 Make Harmony between Technology and Nature, and Your Mind will Fly Free as a Bird Annals \& Proceedings of DAAAM International 2011

\title{
SIMULATION OF THE RESIDENTIAL PHOTOVOLTAIC SYSTEM EXPANSION IMPACT ON THE VOLTAGE PROFILE
}

\author{
KNEZEVIC, G[oran]; FEKETE, K[resimir] \& NIKOLOVSKI, S[rete]
}

\begin{abstract}
Distributed Generation (DG) can provide voltage improvement but also can cause over-voltages in radial distribution networks. This paper investigates an impact of the residential photovoltaic system expansion on the voltage profile of the observed feeder. Model of the expanded photovoltaic system and local distribution network is made in DigSILENT Power Factory software. In order to investigate if voltage limits are violated, voltage profile analysis is performed for different levels of DG penetration and residential consumption. Simulations are repeated when standard transformer is replaced with OLTC transformer.
\end{abstract}

Key words: voltage profile, distributed generation, photovoltaic system, computer model

\section{INTRODUCTION}

Distributed Generation (DG) can be defined as small-scale generation, which is not directly connected to the bulk transmission system and is not centrally dispatched (Keane \& O’Malley, 2005). When it was planning, the distribution system was assumed that electric power always flows from the secondary winding of the transformers in substations to the end of feeders (Naka et al., 2001). With the recently introduced distributed generation, bidirectional power flows should now be incorporated in design and operation criteria of the distribution network which becomes an active system with both energy generation and consumption ( $\mathrm{Vu}$ Van et al., 2003). The distribution generation has significant impact on the power flow, voltage profile and power quality which can manifest itself either positively or negatively, depending on the distribution system operation and distributed generator characteristics.

This paper investigates an impact of the expansion of the residential photovoltaic systems on the voltage profile of the observed feeder. Measurements show that the first $10 \mathrm{~kW}$ residential photovoltaic (PV) system connected to the lowvoltage distribution network in Croatia does not have negative impact on the voltage profile. The use of the residential PV system is increasing. What will happen if the large number of PV plants are connected to the same distribution feeder? Because they are geographically close to each other, the period of maximum production would practically take place in all the PV plants at the same time. The model of expanded residential photovoltaic system and local distribution network is made in order to investigate if voltage limits specified in internal Croatian grid code are violated.

The voltage issues related to the installation of DG in distribution networks have been discussed in several papers. In literature (Baker \& De Mello, 2000) the impact of DG on voltage regulation and losses were analyzed. The impact of DG on voltage regulation by Load Tap Changing (LTC) transformer was studied in literature (Chensong \& Baghzou, 2004).The paper shows that DG can cause under-voltages and over-voltages if proper LTC tap transformer controls are not applied.

\section{DESCRIPTION OF THE SITE AND THE COMPUTER MODEL}

The PV plant studied in this paper is a $10 \mathrm{~kW}$ residential system located in Zagreb, Croatia. The system is composed of $56 \mathrm{PV}$ modules (42 of $170 \mathrm{~W}$ and 14 of $175 \mathrm{~W}$ ) connected to four strings. Every string is then connected to a string inverter. There are three string inverters of $3000 \mathrm{VA}$ maximal AC power and one inverter of 4200 VA maximal AC power. The inverters are then connected via the electrical switchboard to the three phase LV distribution grid of 230/400 V. The power factor that is adjusted for the PV system is 1 and this value is used also in the further simulations. The PV plant is located in the residential part of the city where similar family houses prevail. Data from this actual PV plant is used to create computer model of distribution grid with incorporated PV plants. DigSILENT Power Factory software is used to create computer model.

The PV plant is connected to the distribution grid as a part of the radial feeder connected to the transformer station 10/0.4 $\mathrm{kV}$. In the simulation model, three radial feeders are connected to the $0.4 \mathrm{kV}$ side of the transformer station as shown in Fig. 1 . It is the most common situation in the residential distribution grid in Croatia. It is assumed that 20 consumers (households) are fed from one radial feeder. Transformers data are: 10/0.4 $\mathrm{kV}$, rated power $\mathrm{Sn}=630 \mathrm{kVA}$, short circuit voltage uk\% $=$ $6 \%$. The LV network where the PV plant is connected is an overhead line ACSR $35 \mathrm{~mm} 2$ with the following characteristics: $\mathrm{R}=0.835 \mathrm{Ohm} / \mathrm{km}$ and $\mathrm{X}=0.3 \mathrm{Ohm} / \mathrm{km}$. External distribution grid that is connected to the $10 \mathrm{kV}$ side of the transformer is modeled with its maximal and minimal shortcircuit powers: $\mathrm{Sk}^{\prime \prime} \max =50 \mathrm{MVA}$ and $\mathrm{Sk}^{\prime \prime} \min =5.2 \mathrm{MVA}$.

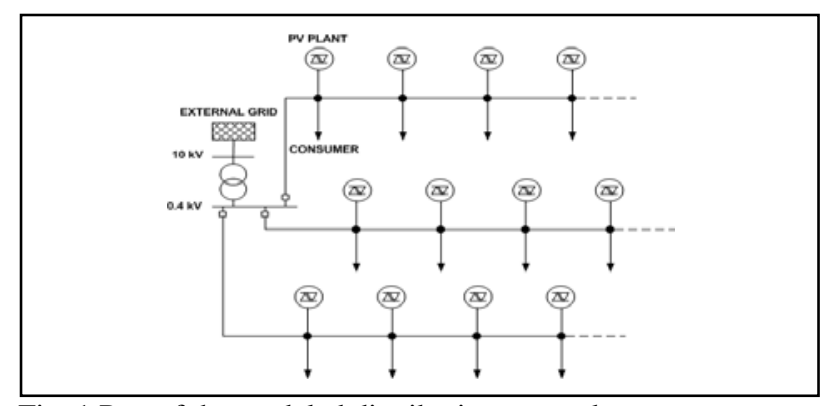

Fig. 1.Part of the modeled distribution network

\section{SIMULATION RESULTS}

Simulations are performed in DigSILENT Power Factory software, Version 14.1. Limitation of the proposed model is an absence of the real stochastic data for PV production and residential consumption, thus simulation is provided for different assumed levels of DG penetration and residential consumption. Generation of the individual PV system changes from 0 to $10 \mathrm{~kW}$ in five steps. Residential consumption changes also in five steps from 1 to $5 \mathrm{~kW}$. In this way, 25 different 
scenarios are simulated. For each scenario, voltage values are compared with voltage limits which are determined by Croatian grid code. Acceptable deviation of the voltage in Croatian distribution low-voltage networks is $\pm 10 \%$. Since all three feeders have the same characteristics, we will observe voltage profiles only for one feeder. Results of the performed voltage analysis for different scenario are shown in Table 1. Mark "X" stands for the scenarios in which voltage limits are violated.

\begin{tabular}{|c|c|c|c|c|c|}
\hline \multirow{2}{*}{$\begin{array}{l}\text { Residential } \\
\text { Load (kW) }\end{array}$} & \multicolumn{5}{|c|}{ Generation of individual PV system (kW) } \\
\hline & 0 & 2.5 & 5 & 7.5 & 10 \\
\hline 1 & $\bar{V}$ & $\bar{V}$ & $\sqrt{2}$ & $x$ & \\
\hline 2 & $\sqrt{ }$ & $\sqrt{ }$ & $\sqrt{ }$ & $\sqrt{2}$ & X \\
\hline 3 & $\sqrt{2}$ & $\sqrt{ }$ & $\sqrt{ }$ & $\sqrt{2}$ & 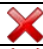 \\
\hline 4 & X & $\sqrt{2}$ & $\sqrt{ }$ & $\sqrt{2}$ & \\
\hline 5 & X & $\sqrt{2}$ & $\sqrt{ }$ & $\sqrt{2}$ & $\sqrt{2}$ \\
\hline
\end{tabular}

Tab. 1.Evaluation of voltage limits violence for each scenario

Voltage profiles for different level of photovoltaic system production when residential consumption is equal $1 \mathrm{~kW}$ are presented on Fig. 2. The highest over-voltage (1.162 p.u.) appears in scenario where production of the individual photovoltaic system is $10 \mathrm{~kW}$ and residential consumption is equal $1 \mathrm{~kW}$.

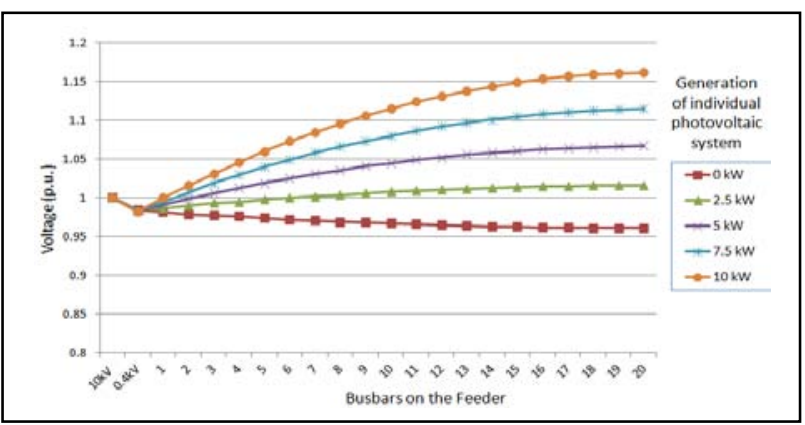

Fig. 2.Voltage profiles for different level of DG production while residential consumption is equal $1 \mathrm{~kW}$

Voltage profiles for different level of photovoltaic system production when residential consumption is equal $5 \mathrm{~kW}$ are presented on Fig. 3. The lowest voltage (0.858 p.u.) for the feeder edge consumer appears in scenario where there is no production of photovoltaic system and residential consumption is equal $5 \mathrm{~kW}$.

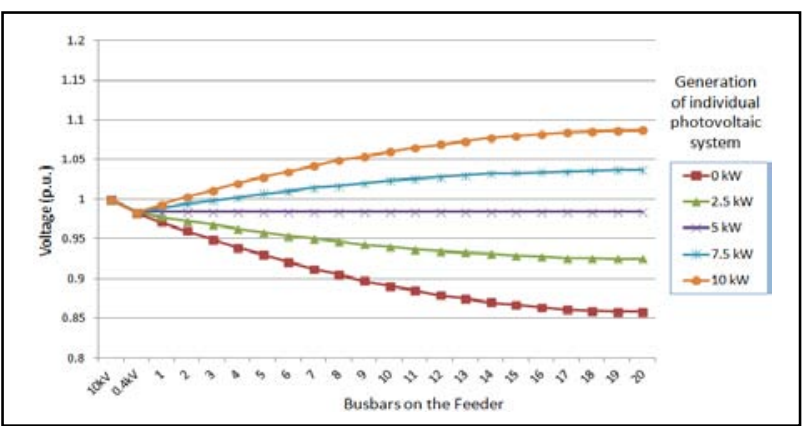

Fig. 3.Voltage profiles for different level of DG production while residential consumption is equal $5 \mathrm{~kW}$

In the simulation model, standard transformer is now replaced with on-load tap-changing (OLTC) transformer which has thyristor-assisted tap changer. Simulations for two scenarios with highest over-voltage and lowest under-voltage are repeated and results are presented in Fig 4 and Fig 5. Results show that voltage limits are not violated when OLTC transformer is used.

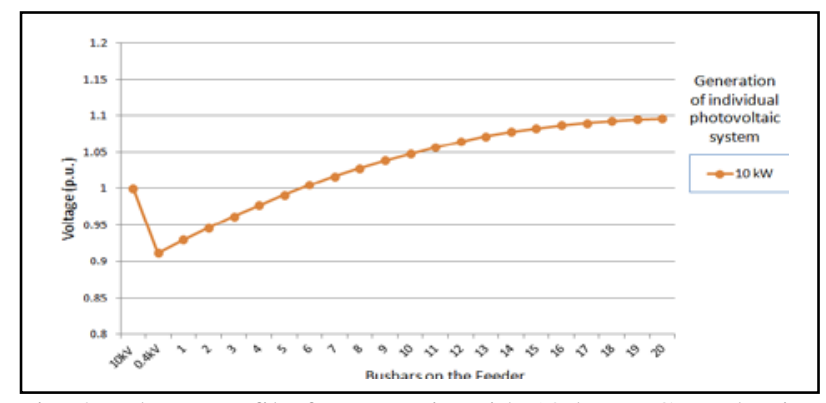

Fig. 4.Voltage profile for scenario with $10 \mathrm{~kW}$ DG production and $1 \mathrm{~kW}$ of residential consumption using OLTC transformer

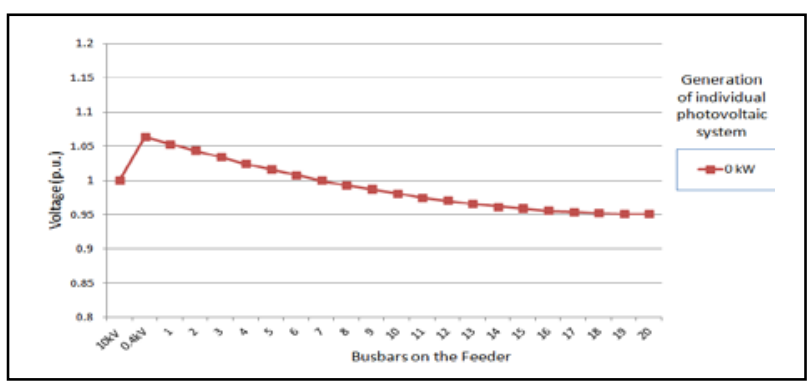

Fig. 5.Voltage profile for scenario with no DG and $5 \mathrm{~kW}$ of residential consumption using OLTC transformer

\section{CONCLUSION}

In this paper, the impact of the residential photovoltaic system expansion on voltage profile of the observed feeder is studied. Simulation results show that standard distribution transformer has to be replaced with OLTC transformer in order to keep voltage values inside the limits which are defined by Croatian grid code. In further work, stochastic analysis of PV production and residential consumption would be done based on measurement data in order to obtain more realistic scenarios for voltage analysis. Additionally, study of PV's harmonic impacts on the system voltage will be done.

\section{REFERENCES}

Barker, P.P. \& De Mello, R.W. (2000). Determining the impact of distributed generation on power systems. I. Radial distribution systems, Proceedings of IEEE Power Engineering Society Summer Meeting, Seattle, Washington, USA, ISSN 15213765, ISBN 0-7803-6420-1, vol. 3, pp. 1645-1656, Published by IEEE, Piscataway, New Jersey

Chensong D. \& Baghzouz, Y. (2004). Impact of distributed generation on voltage regulation by LTC transformer, Proceedings of 11th International Conference on Harmonics and Quality of Power, Lake Placid, New York, USA, ISBN 0-7803-8746-5, pp. 770-773, Published by IEEE, Piscataway, New Jersey

Keane, A. \& O’Malley, M. (2005). Optimal Allocation of Embedded Generation on Distribution Networks, IEEE Trans. Power Systems, Vol. 20, No. 3, (August 2005), pp. 1640 - 1646, ISSN 0885-8950

Naka, S.; Genji, T. \& Fukuyama, Y. (2001) Practical equipment models for fast distribution power flow considering interconnection of distributed generator, Proceedings of IEEE Power Engineering Society Summer Meeting, Vancouver, Canada, ISBN 0-7803-7173-9, Vol. 2, pp. 1007-1012, Published by IEEE, Piscataway, New Jersey

Vu Van, T.; Driesen, J. \& Belmans, R. (2003). Improving voltage stability with the connection of distributed generation, Available from:

http://www.esat.kuleuven.be/electa/publications/fulltexts/pu b_1110.pdf, Accessed: 2011-09-03 